\title{
ANALYSIS OF THE VIDEOLAPAROSCOPY POTENTIALITY IN THE SURGICAL TREATMENT OF THE BOWEL OBSTRUCTION
}

\author{
Tiago Leal GHEZZI ${ }^{1}$, Laura MOSCHETTI ${ }^{2}$, Oly Campos CORLETA ${ }^{1,2,3}$, \\ Gabriela Pilau de ABREU $^{3}$ and Laís Pilau de ABREU $^{3}$
}

\begin{abstract}
Context - Laparotomy is the gold standard treatment of patients with intestinal obstruction without response to clinical management. Nowadays, literature has been demonstrating the feasibility of videolaparoscopy in the treatment of intestinal obstruction. Objectives - To report the clinical-epidemiological profile of patients with intestinal obstruction submitted to surgery and verify the presence of contraindications for laparoscopy. Methods - It was done a observational, descriptive and retrospective study including adults patients with intestinal obstruction submitted to surgery at Hospital de Clínicas de Porto Alegre, RS, Brazil, between January of 2004 and October of 2008. Results - It was included 135 patients in the study, with a total of 126 patients submitted to open surgery and 9 to laparoscopy. There was similar distribution between gender and the mean age was 59 years ( $\mathrm{SD} \pm 16.9$ ). The most frequent site of obstruction was the small bowel and the most frequent etiology was adhesions. Among the patients submitted to laparotomy, $75.4 \%$ presented with abdominal distention, $68.3 \%$ previous abdominal surgery, $11.9 \%$ body mass index $>30 \mathrm{~kg} / \mathrm{m}^{2}, 4.8 \%$ coagulopathy and 3.2\% hemodynamic instability. Among the 135 patients, only 5 of them presented with none contraindications for videolaparoscopy. Conclusion - The epidemiological findings of this study are similar to the ones of the worldwide literature. Indications of videolaparoscopy in retrospective analyses have the limitation of subjective evaluation of intestinal obstruction, which was included in this study as a relative contraindication to laparoscopy.
\end{abstract}

HEADINGS - Intestinal obstruction. Video-assisted surgery.

\section{INTRODUCTION}

Intestinal obstruction is an affection frequently found throughout the world ${ }^{(16)}$. It represents $15 \%$ of all hospital admissions for abdominal pain, which constitute more than 300.000 hospitalizations per year in United States ${ }^{(1)}$. Intestinal obstruction is a result of mechanical disruption of the transit of intestinal content of the small and the large bowels. Affections involving the small bowel account for $60 \%$ to $80 \%$ of the cases of acute abdominal obstruction ${ }^{(17)}$. Postoperative peritoneal adhesions account for $60 \%$ to $75 \%$ of cases of small bowel in adults ${ }^{(6,10,17)}$. Other causes of intestinal obstruction include malignant neoplasia, herniae, inflammatory bowel diseases and volvulus ${ }^{(8)}$. The result is a surgical entity with a great diversity of presentation usually demanding a large scale of diagnostic methods and therapeutic modalities $^{(7)}$.

Laparotomy has traditionally been the method of choice for surgical treatment in cases with no response to conservative clinical treatment. Other therapeutic methods should be compared to this gold standard approach. Laparotomy allows exposition and visualization of the entire peritoneal cavity according to the patient's body constitution, size and surgical incision orientation.

Through this approach, the diagnostic accuracy for identifying the site and the cause of the obstruction, so as the performance of the definitive treatment, should be close to $100 \%{ }^{(7)}$. With the advent of minimally invasive techniques in the setting of general surgery, the first reports of diagnosis and treatment of intestinal obstruction by laparoscopy appeared ${ }^{(7)}$. In the beginning, prior abdominal surgeries were considered as relative contraindications in the laparoscopical approach. Currently, however, several publications have been demonstrating the feasibility of this approach in intestinal obstruction treatment ${ }^{(5)}$.

The goal of this study was to describe the clinical and the epidemiological profile of patients with intestinal obstruction submitted to emergency surgical treatment in a high volume hospital, as well as to verify the presence of contraindications to laparoscopic approach. 


\section{METHODS}

This is a retrospective observational study of patients with clinical and radiological diagnosis of intestinal obstruction at Hospital de Clínicas of Porto Alegre, RS, Brazil (HCPA). The research concerned adult patients undergoing surgery for intestinal obstruction (CID K56) from January 2004 to October 2008. Data were collected for the following variables: gender, age, coagulopathy $(<100.000$ platelets, prothrombin time $1.5 \mathrm{x}>$ reference value, actived partial thromboplastin time $1.5 \mathrm{x}>$ reference value or fibrinogen $>1 \mathrm{~g} / \mathrm{L}$ ), hemodynamic instability ( $\mathrm{SBP}<90 \mathrm{~mm} \mathrm{Hg}$, DBP $<50 \mathrm{~mm} \mathrm{Hg}$ or signs of poor peripheral perfusion), previous abdominal surgery, body mass index $(\mathrm{BMI})\left(\mathrm{kg} / \mathrm{m}^{2}\right)$, presence of abdominal distention (clinical or radiological criteria), type of abdominal distention (small or large bowel), means of access, presence of intraperitoneal free liquid, vascular intestinal suffering, intestinal perforation, etiology of obstruction, surgery performed, postoperative complications, reintervention, length of hospitalization and death related to surgery proceed (until 30 days after intervention).

Statistical analysis was performed using the 16.0 version of SPSS program. Categorical variables were described through absolute frequency and percentage relative frequency. Symmetric and asymmetric quantitative variables were described through average and standard deviation and through median and minimum-maximum range. This study was submitted to and approved by the research Ethics Committee and Research Group and Graduate of HCPA - protocol number: 08498.

\section{RESULTS}

Initially 138 patients were identified and 3 among them were excluded because medical records were not available. The mean age of the sample composed by 135 patients was 59 years $(\mathrm{SD} \pm 16.94)$. Sixty-eight patients $(50.4 \%)$ were males. Altogether 126 patients underwent conventional surgery and 9 patients were submitted to laparoscopy, 4 of those converted to open approach. Three conversions resulted of technical difficulties and one of intestinal injury during the trocar introduction.

Most patients who underwent open surgery presented abdominal distention during the clinical or radiographic examination (95 patients $=75.4 \%$ ) and history of prior abdominal surgery $(86$ patients $=68.3 \%$ ). Even among those who were treated by laparotomy, 6 patients $(4.8 \%)$ presented coagulopathy, $4(3.2 \%)$ hemodynamic instability and 15 $(11.9 \%)$ were obese $\left(\mathrm{BMI}>30 \mathrm{~kg} / \mathrm{m}^{2}\right)$ (Table 1$)$.

TABLE 1. Criteria of contraindication to video laparoscopy in patients submitted to laparotomy

\begin{tabular}{lc}
\hline Contraindication & $\mathrm{n}(\%)$ \\
\hline Coagulopathy & $6(4.8)$ \\
Hemodynamic instability & $4(3.2)$ \\
Previous abdominal surgery & $86(68.3)$ \\
Obesity (BMI $>30)$ & $15(11.9)$ \\
Abdominal distention & $95(75.4)$ \\
\hline
\end{tabular}

The transoperative findings of 135 patients showed that in 79 cases the site of obstruction was the small bowel, in 50 cases it was the large bowel and 9 patients had frozen abdomen due to extensive peritoneal carcinomatosis. The main cause of intestinal obstruction was adhesions in 58 patients $(43 \%)$. Other causes observed were malignancies $(51$ patients $=$ $37.5 \%$ ), bezoar ( 5 patients $=3.2 \%)$, incarcerated hernias $(4$ patients $=3 \%$ ), volvulus ( 4 patients $=3 \%$ ), Crohn's disease (3 patients $=2.2 \%)$ and others $(10$ patients $=7.4 \%)$. During inventory of peritoneal cavity, it was identified significant distension of the small intestine and large respectively in 92 $(68.1 \%)$ and 30 patients $(22.2 \%)$. Free fluid in the cavity, signs of intestinal vascular suffering and intestinal perforation were observed respectively in $36(26.7 \%), 18(13.4 \%)$ and 7 $(5.2 \%)$ patients (Table 2 ).

TABLE 2. Transoperative findings

\begin{tabular}{lc}
\hline Site of obstruction & $\mathbf{n}(\%)$ \\
\hline Small bowel & $79(58.8)$ \\
Large bowel & $50(37.0)$ \\
Frozen abdomen & $6(4.4)$ \\
Cause of obstruction & \\
Adhesions & $58(43.0)$ \\
Hernia & $4(3.0)$ \\
Volvulus & $4(3,0)$ \\
Neoplasia & $51(37.5)$ \\
Crohn's disease & $3(2.2)$ \\
Bezoar & $5(3.7)$ \\
Others & $10(7.4)$ \\
Small bowel distention & $92(68.1)$ \\
Large bowel distention & $30(22.2)$ \\
Free liquid & $36(26.7)$ \\
Vascular suffering & $18(13.4)$ \\
Intestinal perforation & $7(5.2)$ \\
\hline
\end{tabular}

The most frequent surgery was adhesiolyse used as single procedure in 42 cases $(31.1 \%)$ and associated to other surgeries in different situations. Other surgeries performed also include intestinal resection and anastomosis (26 patients $=19.2 \%)$, intestinal resection and external diversion (21 patients $=15.5 \%)$, external diversion alone (12 patients $=9 \%)$, internal diversion alone $(9$ patients $=6.6 \%)$, and enterotomy/enterorrhaphy ( 8 patients $=6 \%$ ), non-therapeutic laparotomy $(7$ patients $=5.2 \%)$, other procedures $(5$ patients $=3.7 \%$ ), distortion of intestinal volvulus with or without pexia ( 3 patients $=2.2 \%$ ) and reduction and repair of hernia $(2$ patients $=1.5 \%)($ Table 3$)$.

TABLE 3. Surgeries performed

\begin{tabular}{lc}
\hline Surgery performed & $\mathbf{n}(\%)$ \\
\hline Adhesiolysis & $42(31.1)$ \\
Resection + anastomosis & $26(19.2)$ \\
Resection + external derivation & $21(15.5)$ \\
Internal derivation & $9(6.6)$ \\
External derivation & $12(9.0)$ \\
Reduction and repair of hernia & $2(1.5)$ \\
Enterotomy & $8(6.0)$ \\
Distortion with or without pexis & $3(2.2)$ \\
Others & $5(3.7)$ \\
Non-therapeutic & $7(5.2)$ \\
\hline
\end{tabular}


Clinical and surgical postoperative complications occurred respectively, in $49(36.3 \%)$ and $63(46.6 \%)$ patients. Among the surgical complications, those of infectious etiology were the most commonly observed ( 28 patients $=20.7 \%$ ). The average length of hospital stay was 15 days, ranging from 2 to 85 days. Surgical reintervention was necessary in 28 patients $(20.7 \%)$ and death was the outcome observed in 26 patients $(19.3 \%)$.

\section{DISCUSSION}

The epidemiological profile of the sample of this research is similar to that observed by other authors in the literature. Franklin Jr. et al. (7) in a study about 167 patients with intestinal obstruction treated by laparosocopy observed similar distribution of gender ( $47 \%$ men) and age (62 years). As observed by Suh et al. ${ }^{(17)}$, the main site of intestinal obstruction in our study was the small bowel $(58.8 \%)$, followed by the colon $(37 \%)$. Like other authors ${ }^{(1,4,8,11,13)}$, intestinal adhesions were the main cause of intestinal obstruction in our series, with $43 \%$ of cases. Unlike in developed countries and certain regions of Africa, where respectively hernia and volvulus of the colon represent the second leading cause of intestinal obstruction ${ }^{(1,}$ ${ }^{9)}$, we observed high proportion of cancer incidence. We think that this is due to the socio-economic context of our country, in which patients seek medical care in large emergencies of public hospitals with intra-abdominal tumors in advanced stage of evolution ${ }^{(3)}$.

Historically, the presence of hemodynamic instability and/or established coagulopathy, as well as peritonitis, obesity, previous abdominal surgery, pelvic radiotherapy and/or abdominal, and abdominal distention were considered absolute or relative contraindications to elective laparoscopic approach, specially in emergency situations ${ }^{(2,18)}$. Recently, the increasing of surgeons' experience and the development of new technologies have made possible the laparoscopic approach in patients with previously contraindication to laparoscopy ${ }^{111}$. 19). The introduction of mechanical suturing staplers, forceps more delicate and less damaging to the bowel loops and new instruments for hemostasis contribute significantly to increase the safety and efficacy of laparoscopy in different clinical situations ${ }^{(16)}$. Optimization of the conservative clinical treatment, specially with the use of nasogastric $(\mathrm{NG})$ tube for decompression of the bowel before surgery, and the implementation of pneumoperitoneum using open through trocar introduced away from prior scars allow the completion of a safer laparoscopic procedure ${ }^{(14)}$. The development of laparoscopic bariatric surgery ${ }^{(15)}$ and the demonstration of favorable results in morbidly obese patients undergoing emergency laparoscopy ${ }^{(12)}$ reinforce the applicability of this approach in the treatment of intestinal obstruction.

According to the literature, patients without signs of peritonitis and with unsatisfactory response to clinical treatment are possible candidates for laparoscopic approach in the treatment of intestinal obstruction. In such cases, it is important to evaluate the diameter of the intestinal loop, the degree of abdominal distention and the site of obstruction (proximal or distal). The finding of a loop of small bowel diameter exceeding $4 \mathrm{~cm}$ was associated to a higher rate of conversion. Patients with distal or full distension have higher rates of intraoperative complications and conversion as well as patients with poor response to conservative treatment with NG tube ${ }^{(14)}$.

In our series only five patients $(3.8 \%)$ have none of these alleged contra-indications. Fifty-seven patients $(42.5 \%)$ had only one of these criteria, among these there were 25 cases of abdominal distention, 29 previous abdominal surgery, 1 coagulopathy, 1 hemodynamic instabillity and prior radiotherapy. Among the other, 59 patients (44\%) had two criteria, 11 patients $(8.2 \%)$ had three criteria and 2 patients $(1.5 \%)$ had four criteria for contraindication to videolaparoscopic (Figure 1). Only 9 patients were submitted to laparoscopy, with 5 of those treated successfully and without any complication postoperatively. Other 4 required conversion to open technique, mostly due to technical difficulties.

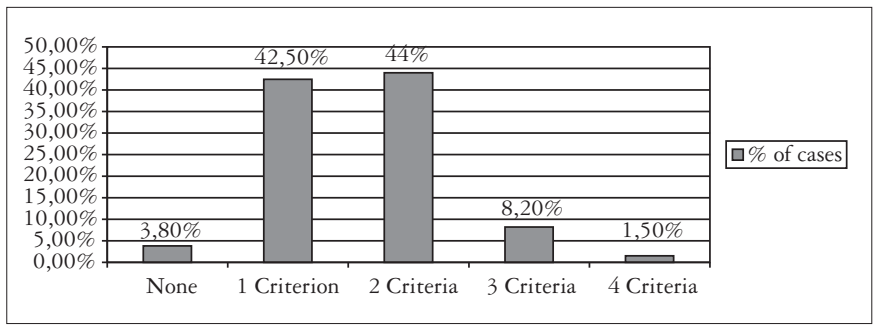

FIGURE 1. Criteria of absolute and relative contraindication for laparoscopy

Once our study is retrospective and was carried out based on data stored in the hospital records, there are limitations in relation to the precise assessment of the abdominal distention degree and its site, fact that do not allow an accurate inference of how many patients underwent laparotomy really have real contraindication to laparoscopic. considering that five patients did not present any criterion of contraindication and that 54 patients had only one criterion (abdominal distention, or previous surgery) and that with the use of NG tube a partial involution can be part of the abdominal distention case, we believe that the laparoscopic sample would have a greater potential of use in relation to how it has been used today.

Wullstein et al. ${ }^{(19)}$ comparison study of surgical treatment by laparotomy and laparoscopy in patients with obstruction of small bowel, showed lower rate of postoperative complications, faster recovery of intestinal transit and shorter stay in hospital. Considering the peritoneal adhesions as the main cause of intestinal obstruction and its lower formation rate during laparoscopic surgery ${ }^{(16)}$, we reinforce the potential of laparoscopy as a promising method of approach to intestinal obstruction.

In summary, laparoscopy has been a viable, safe and effective approach when performed by experienced surgeons, with appropriate instrumental and in carefully selected cases of intestinal obstruction. 
Ghezzi TL, Moschetti L, Corleta OC, Abreu GP, Abreu LP. Análise do potencial da videolaparoscopia no tratamento cirúrgico da obstrução intestinal. Arq Gastroenterol. 2010;47(2):148-51.

RESUMO - Contexto - A laparotomia é considerada o método de escolha para o tratamento cirúrgico de pacientes com obstrução intestinal sem resposta ao tratamento clínico conservador. Atualmente, no entanto, diversas publicações têm demonstrado a viabilidade da videolaparoscopia no tratamento da obstrução intestinal. Objetivo - Descrever o perfil clínicoepidemiológico de pacientes com obstrução intestinal submetidos ao tratamento cirúrgico e verificar a presença de contraindicações para laparoscopia. Método - Estudo observacional, descritivo e retrospectivo com pacientes adultos submetidos a tratamento cirúrgico por obstrução intestinal no Hospital de Clínicas de Porto Alegre, RS, no período de janeiro 2004 a outubro 2008. Resultados - Foram estudados 135 pacientes, 126 dos quais tratados por laparotomia e 9 por videolaparoscopia. Observou-se distribuição semelhante entre os sexos e idade média de 59 anos ( $\mathrm{DP} \pm 16,9$ ). Intestino delgado e aderências intestinais representaram respectivamente, o principal sítio e causa de obstrução. Dos pacientes submetidos a laparotomia, 75,4\% apresentavam distensão abdominal, 68,3\% história de cirurgia abdominal prévia, 11,9\% índice de massa corpórea $>30 \mathrm{~kg} / \mathrm{m}^{2}, 4,8 \%$ coagulopatia e 3,2\% instabilidade dinâmica. Dos 135 pacientes, somente 5 não apresentavam contraindicação para videolaparoscopia. Conclusão - Os dados epidemiológicos deste estudo são semelhantes aos observados na literatura mundial. A indicação de videolaparoscopia em análises retrospectivas tem como grande limitante a avaliação subjetiva da distensão abdominal, que nesse trabalho foi incluída como contraindicação relativa para videolaparoscopia.

DESCRITORES - Obstrução intestinal. Cirurgia vídeo-assistida.

\section{REFERENCES}

1. Cappell MS, Batke M. Mechanical obstruction of the small bowel and colon. Med Clin North Am. 2008;92:575-97.

2. Corleta OC. Obstrução intestinal. In: Cavazzola LT, Souza da Silva R, Bregeiron R, Menegotto R, Figueiredo F, editores. Condutas em cirurgia geral. Porto Alegre: Artmed; 2008. p.380-7.

3. Cury MS, Forones NM. Neoplasias primárias múltiplas em pacientes com câncer colorretal. Arq Gastroenterol. 2000;37:89-92.

4. Essani R, Bergamaschi R. Laparoscopic management of adhesive small bowel obstruction. Tech Coloproctol. 2008;12:283-7.

5. Farinella E, Cirocchi R, La Mura F, Morelli U, Cattorini L, Delmonaco P, Migliaccio C, De Sol AA, Cozzaglio L, Sciannameo F. Feasibility of laparoscopy for small bowel obstruction. World J Emerg Surg. 2009;4:3.

6. Fevang BT, Fevang J, Stangeland L. Complications and death after surgical treatment of small bowel obstruction: a 35-year institutional experience. Ann Surg. 2000;231:529-37.

7. Franklin ME Jr, Gonzalez JJ Jr, Miter DB, Glass JL, Paulson D. Laparoscopic diagnosis and treatment of intestinal obstruction. Surg Endosc. 2004;18:26-30.

8. Hayanga AJ, Bass-Wilkins K, Bulkley GB. Current management of small-bowel obstruction. Adv Surg. 2005;39:1-33.

9. Hellinger MD, Steinhagen RM. Colonic volvulus. In: Wolff BG, Fleshman JW, Beck DE, Pemberton JH, Wexner SD, editors. The ASCRS textbook of colon and rectal surgery. New York: Springer Science + Business Media; 2007. p.286-97.
10. Kahi CJ, Rex DK. Bowel Obstruction and pseudo-obstruction. Gastroenterol Clin N Am. 2003;32:1229-47.

11. Kirshtein B, Roy-Shapira A, Lantsberg L, Avinoach E, Mizrahi S. Laparoscopic management of acute small bowel obstruction. Surg Endosc. 2005;19:464-7.

12. Köckerling F, Schug-Pass C, Grund S. [Laparoscopic appendectomy: the new standard?]. Chirurg. 2009;80:594-601.

13. Moran BJ. Adhesion-related small bowel obstruction. Colorectal Dis. 2007;9:39-44

14. Nagle A, Ujiki M, Denham W, Murayama K. Laparoscopic adhesiolysis for small bowel obstruction. Am J Surg. 2004;187:464-70.

15. Nguyen NT, Goldman C, Rosenquist CJ, Arango A, Cole CJ, Lee SJ, Wolfe BM Laparoscopic versus open gastric bypass: a randomized study of outcomes, quality of life, and costs. Ann Surg. 2001;234:279-89.

16. Seid VE, Imperiale AR, Araújo SE, Campos FGCM, Souza Jr AHS, Kiss DR, Cecconello I. A videolaparoscopia no diagnóstico e tratamento da obstrução intestinal. Rev Bras Coloproctol. 2007;27:228-34.

17. Suh RS, Maglinte DDT, Lavonas FJ. Emergency abdominal radiography: discrepancies of preliminary and final interpretation and management relevance. Emerg Radiol. 1995;2:1-4.

18. Szomstein S, Menzo EL, Simpfendorfer C, Zundel N, Rosenthal RJ. Laparoscopic lysis of adhesions. World J Surg. 2006;30:535-40.

19. Wullstein C, Gross E. Laparoscopic compared with conventional treatment of acute adhesive small bowel obstruction. Br J Surg. 2003;90:1147-51.

Received 27/7/2009. Accepted 27/8/2009. 